\title{
Nomeando o inominável. A problematização da violência obstétrica e o delineamento de uma pedagogia reprodutiva contra-hegemônica
}

Naming the nameless. The problematization of obstetric violence and the construction of a counterhegemonic reproductive pedagogy

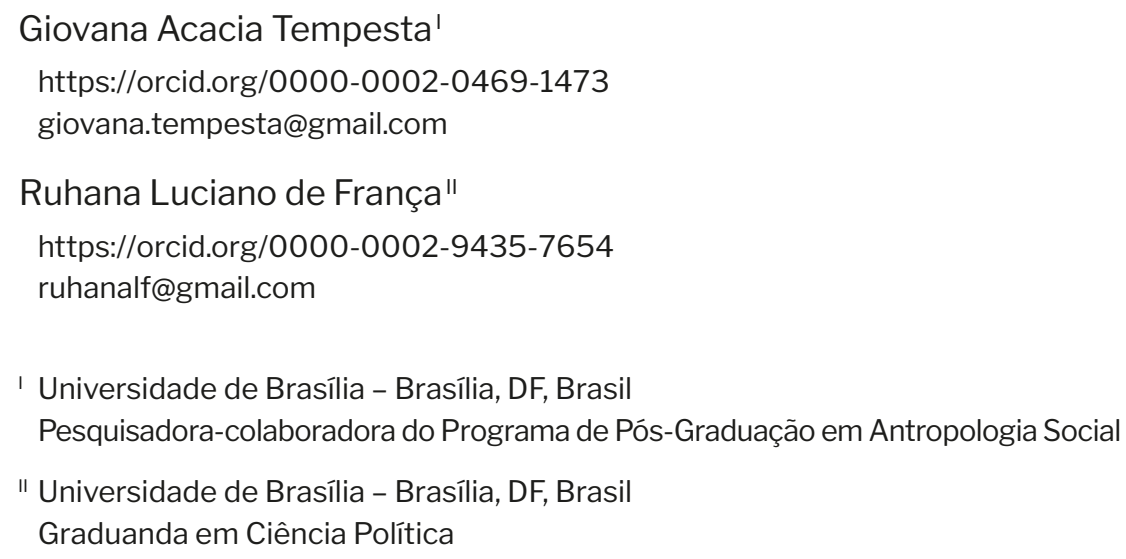




\title{
Resumo
}

No bojo do movimento de humanização do parto e nascimento no Brasil, doulas e educadoras perinatais vêm se apropriando de certos conhecimentos biomédicos e combinando-os a conhecimentos "tradicionais" ou "alternativos" em torno do parto. Na última década, muitas delas passaram a falar abertamente sobre violência obstétrica e a legitimar o direito das mulheres a narrar o sofrimento experimentado, compondo um outro referencial de cuidado, articulado a uma pedagogia reprodutiva contra-hegemônica. A partir de uma mirada interseccional, propomos pensar a doulagem associada à educação perinatal como prática de problematização dos pressupostos culturais mais gerais em torno dos quais se organizam as hierarquias reprodutivas vigentes e o modelo obstétrico hegemônico. Sugerimos que a presente contribuição permite ampliar o debate sobre governança reprodutiva para além do fundamento liberal do paradigma dos direitos sexuais e reprodutivos, de modo a acolher as premissas da luta por justiça reprodutiva.

Palavras-chave: hierarquias reprodutivas; violência obstétrica; doulagem; educação perinatal.

\begin{abstract}
In the midst of the humanization movement for childbirth and birth in Brazil, doulas and perinatal educators have been appropriating certain biomedical knowledge and combining it with "traditional" or "alternative" knowledge around childbirth. In the past decade, many of them come to speak openly about obstetric violence and to legitimize the right of women to narrate the suffering experienced, composing another paradigma of care, articulated to a conter-hegemonic reproductive pedagogy. From an intersectional view, we propose to think of the doulage associated with perinatal education as a practice of problematizing the more general cultural assumptions around which the current reproductive hierarchies and the hegemonic obstetric model are organized. We suggest that the present contribution makes it possible to broaden the debate on reproductive governance beyond the liberal foundation of the sexual and reproductive rights paradigm, in order to accommodate the premises of the struggle for reproductive justice.
\end{abstract}

Keywords: reproductive hierarchies; obstetric violence; doula; perinatal education. 


\section{Preâmbulo ${ }^{1}$}

Desde o final do século XX, várias pesquisadoras vêm chamando a atenção para a necessidade de apreender as experiências reprodutivas nos termos de uma política da reprodução, como atesta a coletânea Conceiving the New World Order: the global politics of reproduction, organizada por Ginsburg e Rapp (1995). Ademais, a proposição de que as atividades associadas à reprodução consistem em trabalho não remunerado - uma modalidade de trabalho crucial para a configuração e a consolidação do sistema capitalista (Federici, 2017) - convida a mirar seu fundamento propriamente político, com frequência obliterado pelas noções ocidentais hegemônicas de domesticidade e privacidade.

O parto é central para a discussão sobre governança reprodutiva porque cada experiência de dar à luz pode ser decisiva para a vida das mulheres, a depender da posição ocupada por elas na estrutura reprodutiva observada, uma vez que experiências positivas podem acentuar o desejo de ter mais filhos, ao passo que experiências negativas podem aniquilar esse desejo, acarretar problemas de saúde física e mental e até mesmo causar a morte. ${ }^{2}$

Nos anos 1980, Martin (2006) demonstrou como a percepção do parto partilhada por mulheres comuns corresponde à visão que a medicina delineou sobre o corpo e os eventos reprodutivos femininos. Outrossim, neste início de século XXI, em todo o mundo a perspectiva biomédica sobre as capacidades reprodutivas femininas convive com a parteria tradicional comunitária e com

1 O presente artigo retoma e desenvolve ideias apresentadas por Giovana Tempesta em eventos acadêmicos e também na monografia de conclusão de curso elaborada por Ruhana de França, sob orientação de Giovana. Gostaríamos de agradecer às coordenadoras do ST 05 da VII ReACT e do GT 11 da XIII RAM; à professora Flávia Biroli, parecerista da citada monografia; ao Coletivo de Antropologia e Saúde Coletiva da UnB (CASCA); e ao Comitê de Ética em Pesquisa em Ciências Sociais Humanas e Sociais da UnB, que autorizou a realização da pesquisa coordenada por Giovana. Agradecemos especialmente às doulas que têm colaborado com a pesquisa. Todavia, a responsabilidade por quaisquer imprecisões ou falhas porventura existentes no texto é exclusivamente das autoras.

2 Carneiro (2015) etnografou grupos de preparo de gestantes no estado de São Paulo e indicou a centralidade que a experiência de parto adquiriu entre camadas médias urbanas nas últimas décadas. Ainda que, comparativamente, a experiência de parto em si possa não ser tão valorizada por mulheres de classes populares, como aponta Hirsch (2019), parece-nos que a vigência de uma hierarquia reprodutiva condiciona a qualidade da assistência que mulheres de diferentes segmentos socioeconômicos receberão, o que provoca impactos relevantes para o conjunto das mulheres brasileiras, como veremos. 
outros modelos de assistência que emergiram na segunda metade do século XX, como o parto acompanhado por enfermeiras obstétricas. Em meio a esse contexto de disputas em torno do controle sobre o parto, emergiu a figura da doula e educadora perinatal.

Doulas e educadoras perinatais são profissionais que prestam informações qualificadas e apoio físico e emocional durante a gestação, o trabalho de parto e o pós-parto; geralmente sua prática é associada a métodos não farmacológicos de alívio da dor durante o trabalho de parto, tais como massagens e exercícios respiratórios e com bola de fisioterapia. A Organização Mundial de Saúde (OMS) já reconheceu a relevância desse tipo de suporte, que se constitui em torno da premissa de que a mulher é a protagonista da gestação e do parto. Trata-se de uma atuação contra-hegemônica, que vem explicitando e problematizando ações classificadas como "violência obstétrica", pois muitas doulas se percebem - e são percebidas pelos profissionais de saúde - como os atores mais propensos a testemunhar essa modalidade de violência, a qual atinge diferencialmente mulheres de distintos pertencimentos étnico-raciais e socioeconômicos. Nesse sentido, sugerimos que a doulagem associada à educação perinatal convida a situar as estratégias de governança reprodutiva no horizonte da justiça reprodutiva, de modo a superar as hierarquias e iniquidades existentes.

Violência obstétrica consiste em uma modalidade específica de violência que ocorre no âmbito da assistência prestada a uma mulher ou pessoa trans ao longo da gestação, trabalho de parto, eventual abortamento e período pós-parto. A pesquisadora e ativista Ligia Moreitas Sena (2016) reuniu relatos de mulheres de várias regiões do Brasil que classificaram como violentas suas próprias experiências de gestação, parto e pós-parto, tanto na rede pública como em instituições privadas. De acordo com Sena, violência obstétrica abrange: tratamento infantilizador, paternalista, omisso, manipulador ou agressivo; impedimento da presença de acompanhante (direito assegurado pela lei federal $n^{\circ}$ 11.108/2005 [Brasil, 2005]); ausência de acolhimento empático e de escuta qualificada; negativa de prestação de esclarecimentos adequados; imposição da cesariana; separação por longos períodos entre mãe e recém-nascido, associada à ausência de incentivo à amamentação; internação prolongada sem a apresentação de justificativas; uso arbitrário da anestesia, desconsiderando-se os pedidos da mulher; realização de procedimentos técnicos sem 
consulta à mulher ou sem o seu consentimento expresso, ou ainda como forma de retaliação explícita; além de abuso sexual.

Todavia, cabe destacar o caráter situacional dessa categoria, pois algumas intervenções podem ser vistas, num primeiro momento, como não problemáticas ou mesmo positivas por mulheres das classes populares (Hirsch; Mendonça, 2020). Mas, como explicaremos adiante, tal naturalização de práticas intervencionistas parece configurar uma expressão do funcionamento pervasivo das hierarquias reprodutivas (Mattar; Diniz, 2012).

Observamos que a maioria dos textos antropológicos disponíveis que tratam do tema do parto humanizado e da violência obstétrica adotam uma perspectiva que privilegia o gênero e deixam em segundo plano as articulações com outros padrões de opressão, ou então se concentram em certas dicotomias conceituais (tradicional-científico, natural-artificial, camadas médias-camadas populares $)^{3}$ ou ainda desconfiam de saída do potencial transformador da proposta da "humanização", devido ao caráter elitista dos primórdios do movimento. A despeito da inegável contribuição que esses trabalhos representam, pensamos que abordagens como essas podem acabar obliterando as sutilezas, a complexidade e as potencialidades contingentes de um movimento tão heterogêneo e dinâmico. De nossa parte, pretendemos adotar a mirada interseccional, que nos leva a encarar a problemática da violência obstétrica como elemento constitutivo de uma política da reprodução hierarquizada, entendida em termos sistêmicos.

Iniciaremos a reflexão com a apresentação dos fundamentos da perspectiva interseccional que está sendo adotada. Faremos então uma reconstituição histórica da configuração da natalidade como problema político no Ocidente, entre os séculos XVII e XVIII, passando pela definição do corpo feminino como carente de intervenções e chegando até o modelo obstétrico tecnocrático, característico da segunda metade do século XX. Em seguida trataremos da conquista paulatina, na América Latina e no Brasil, do direito a narrar o sofrimento decorrente da assistência obstétrica, conquista para a qual as doulas contribuíram. Por fim, passaremos à reflexão sobre a doulagem e a educação perinatal

3 Carneiro (2014) já problematizou algumas dicotomias conexas, inspirada nas ideias de Roy Wagner sobre o caráter produtivo das contradições culturais. 
como uma nova tecnologia reprodutiva, que se baseia na atitude de to reclaim (reivindicar e atualizar, como propõe Stengers, 2018) saberes e práticas historicamente marginalizadas.

Nosso solo etnográfico é composto por entrevistas em profundidade realizadas com doulas e educadoras perinatais que atuam no Distrito Federal, ${ }^{4}$ observação de audiências públicas sobre violência obstétrica e sobre a regulamentação da profissão de doula, participação em eventos presenciais e virtuais organizados por doulas e análise de documentos públicos. ${ }^{5}$ Em todo o percurso, buscaremos pontuar as imbricações de classe, raça/etnia, faixa etária e região/territorialidade que constituem as hierarquias reprodutivas vigentes no Brasil.

\section{As hierarquias reprodutivas na perspectiva interseccional}

Aplicada à atenção obstétrica, a noção de dano interseccional proposta por Crenshaw (2002) ajuda a perceber que as desvantagens enfrentadas por um conjunto específico de mulheres interagem com vulnerabilidades preexistentes, engendrando uma dimensão diferente de desempoderamento, na qual se entrecruzam marcadores de gênero, sexualidade, raça/etnia, classe, faixa etária, região geográfica/território, religiosidade e outros.

4 Todas as nossas interlocutoras são doulas e educadoras perinatais; porém, por comodidade de exposição, por vezes utilizaremos apenas o termo doula.

5 As entrevistas foram agendadas previamente, foram realizadas em local reservado (em Brasília), foram gravadas e posteriormente transcritas; todas elas foram precedidas da leitura do Termo de Consentimento Livre e Esclarecido (TCLE) e contaram com a anuência expressa das entrevistadas. Optamos por não registrar características mais detalhadas das doulas a fim de preservar seu anonimato. Em relação às audiências públicas, tomávamos ciência da data e local de realização por meio de mensagens veiculadas em grupos de doulas (redes sociais e aplicativos de celular) ou éramos avisadas individualmente pelas próprias interlocutoras; participamos presencialmente da maioria das audiências aqui consideradas, mas também assistimos a algumas gravações disponíveis nos endereços eletrônicos oficiais. Em todas as audiências tomamos nota em diário de campo e revisamos os arquivos oficiais sempre que foi possível encontrá-los. Muitas vezes conseguimos conversar com algumas interlocutoras durante ou logo após esses eventos e assim tivemos acesso às suas impressões. Por fim, importa informar que ambas as autoras fizemos curso de formação de doula em Brasília e participamos de grupos virtuais de doulas. 
Aprofundando a reflexão sobre o conceito de interseccionalidade, Brah (2006) sugere que a perspectiva interseccional ajuda a apreender os padrões de articulação das múltiplas opressões em torno dos quais se organizam processos locais de subordinação e dominação, que por sua vez estão conectados a relações internacionais de poder. Aqui "articulação" não se refere à simples junção de entidades discretas, mas sim a um movimento transformador de configurações relacionais. A autora defende que as categorias existem nas e por meio das relações entre elas - relações íntimas, recíprocas e contraditórias -, e que nas encruzilhadas produzidas por essas contradições é possível criar estratégias para a mudança. $\mathrm{O}$ foco desse tipo de abordagem não seria, portanto, encontrar uma categoria universal mais determinante que as demais, mas sim buscar as articulações locais entre categorias e práticas de opressão.

Tal perspectiva nos ajuda também a não considerar a obstetrícia e o direito como blocos maciços, pois o papel desempenhado pelos dissidentes de ambos os campos na reforma do modelo obstétrico é significativo. Ademais, o foco nas doulas permite situar sociologicamente as experiências pessoais múltiplas de gestar e parir, bem como acessar princípios e valores (pressupostos culturais) atualizados pela categoria violência obstétrica, o que nos ajuda a compreender o caráter estrutural e estruturante do fenômeno, para além do comportamento individual dos profissionais de saúde, iluminando conexões complexas entre obstetrícia, direito, catolicismo, colonialismo, regime escravocrata, projetos eugenistas, desigualdades sociais estruturais, necropolítica e configuração das subjetividades femininas contemporâneas nas sociedades capitalistas.

É preciso pontuar que as categorias "erro médico" e "lesão corporal" não dão conta daquilo que está sendo classificado e problematizado como violência obstétrica. No epílogo da coletânea Violencia obstétrica en América Latina: conceptualización, experiencias, medición y estrategias, Quattrocchi (2020) resume da seguinte maneira as características principais da violência obstétrica: trata-se de uma violência estrutural (multicausal e multidimensional) no interior de uma ordem social que naturaliza a opressão e que abrange violência de gênero; violência contra o recém-nascido; violação de direitos humanos, do direito à saúde e do direito à saúde reprodutiva; violência institucional; e violência laboral (contra os próprios profissionais de saúde).

Acrescentamos que está em jogo também a reivindicação pelo "direito a narrar" o sofrimento experimentado, que consiste no direito de nar- 
rar-se nos termos colocados pelo discurso jurídico, para que a experiência não seja "privatizada", isto é, diminuída ou silenciada (cf. Segato, 2016). Tudo indica que, em meio ao tensionamento produtivo entre os campos da saúde coletiva e dos direitos humanos, a doulagem associada à educação perinatal se anuncia como um locus promissor para articular o problema da violência obstétrica a uma agenda em torno da noção de justiça reprodutiva.

A discussão que muitas doulas e outros profissionais de saúde vêm realizando enfatiza que o controle médico sobre os corpos femininos não opera da mesma forma para mulheres negras - geralmente representadas como fortes e hipersexualizadas - e para mulheres brancas, representadas como frágeis e recatadas.

Feministas negras apontam que, historicamente, a identidade das mulheres brancas se associa à maternidade na chave do controle dos filhos legítimos, um dos pilares do patriarcado, daí a centralidade da gestação, da gravidez e do direito ao aborto seguro para as classes mais abastadas. Para as mulheres negras escravizadas, porém, o mais importante era o controle sobre os filhos, uma vez que estes não herdavam a condição de seres humanos e via de regra não podiam ser amamentados e cuidados pelas mães (Davis, A., 2016; Gonzalez, 1984; Ribeiro, 2012). Desde o final do século XX, na agenda das feministas negras as questões reprodutivas centrais se situam no horizonte da justiça reprodutiva e concernem a esterilização compulsória, criminalização do aborto, acesso à creche e, mais recentemente, violência obstétrica. Nesses termos, enquanto o acesso a tecnologias de controle de fecundidade proporcionou liberdade e autonomia para as mulheres privilegiadas, foi utilizado contra mulheres racializadas e pobres, atendendo a propósitos racistas e eugenistas, configurando-se, assim, as "hierarquias reprodutivas" ainda vigentes, conforme sintetizado nesta afirmação: "Quanto maior a vulnerabilidade da mulher, mais rude e humilhante tende a ser o tratamento [médico] oferecido a ela" (Diniz et al., 2015).

Assim interpeladas pelas feministas negras e descoloniais, sustentamos que o escopo da discussão deve ser a compreensão aprofundada das condições sociais gerais em meio às quais se organizam as estratégias reprodutivas, visando à transformação de tais condições, e não a mera reafirmação do direito de escolha individual no registro liberal. Será a partir dessa perspectiva que nos aproximaremos do processo internacional de legitimação social do modelo 
obstétrico tecnocrático, ${ }^{6}$ que abrange reações e desdobramentos singulares na América Latina e no Brasil, contextos de democracia frágil. ${ }^{7}$

\section{Controlar e(é) intervir}

De acordo com a pensadora Silvia Federici (2017), a constituição do sistema capitalista se fundamentou em uma nova divisão sexual do trabalho, segundo a qual os homens estariam destinados ao trabalho produtivo (remunerado), enquanto as mulheres estariam destinadas ao trabalho doméstico e reprodutivo (não remunerado). A autora, que dialoga diretamente com as obras de Marx, Foucault e com autoras feministas críticas do feminismo liberal, demonstra que a crise demográfica internacional dos séculos XVI e XVII teria sido a principal causa da transformação da reprodução e do crescimento populacional em assuntos de Estado e em objetos privilegiados do discurso filosófico.

Para lograr regular a procriação, o Estado na Europa se opôs frontalmente ao controle que as mulheres até então exerciam sobre a reprodução, "cercando" saberes e práticas "comuns" (comunais), marginalizando parteiras e aprovando leis e códigos que passavam a classificar práticas de contracepção, aborto, infanticídio e negligência com os bebês como "crimes reprodutivos". A autora explica que, no século XVII, a máquina estava se convertendo no modelo de comportamento social, por isso o desenvolvimento da "máquina humana", esse ente desencantado, teria sido o principal salto tecnológico, o passo mais importante no desenvolvimento das forças produtivas que teve lugar no período de acumulação primitiva. Por outro lado, ela mostra que as mulheres camponesas em geral e as parteiras em particular organizaram formas de

6 De acordo com Davis-Floyd (2001), esse modelo se caracteriza pela ênfase no parto hospitalar, protagonismo do médico, emprego de tecnologias "duras" (tendo a cesariana como sua expressão máxima), separação simbólica entre corpo e mente, definição do corpo humano como máquina e do corpo feminino como inerentemente defeituoso e carente de intervenção.

7 Da perspectiva da ciência política, Biroli (2018) oferece uma importante contribuição ao correlacionar divisão sexual do trabalho, maternidade compulsória e criminalização do aborto aos limites da democracia no Brasil. 
resistência em torno dos "comuns", sendo que algumas das práticas e saberes mobilizados por elas ainda se fazem presentes nos nossos dias. ${ }^{8}$

A intrincada confluência de processos políticos, econômicos e culturais que deu origem, no século XIX, ao modelo do indivíduo racional e da família nuclear heteronormativa articula-se diretamente ao processo de patologização, medicalização e hospitalização do parto.

Em diálogo com a obra de Foucault, pesquisadoras como Rohden (2001), Vieira (2015), Bellón Sánchez (2015) e Vallana Sala (2020) nos auxiliam a compor o quadro geral da captura da reprodução pelo poder-saber obstétrico, que levou mais ou menos dois séculos para se consolidar no Ocidente enquanto campo científico. As autoras demonstram que, no século XIX, a identidade da mulher passou a ser definida como ligada aos órgãos reprodutivos e sua principal função social foi restringida à maternidade. $O$ corpo feminino era visto pela medicina como estranho, inconstante, defeituoso, potencialmente perigoso e patológico, ao passo que a mulher era assim relegada a uma condição passiva em termos simbólicos, políticos, sociais e econômicos, tornando-se alvo privilegiado dos controles públicos, médicos e familiares.

Quanto ao contexto brasileiro, Rohden (2001) e Vieira (2015) explicam que, no final do século XIX, nutria-se um projeto de sociedade medicalizada, que se buscava implementar por meio da batalha contra o "charlatanismo" e do enaltecimento do ideal de cidadão higiênico e controlado. Eram fortes as preocupações governamentais com a descendência, a saúde e o "caráter" dos bebês, visando ao "progresso da nação". De sua parte as parteiras eram associadas às práticas de aborto, contracepção, infanticídio, adultério e abandono de bebês.

Uma vez estabelecido o projeto de marginalização das parteiras, no momento em que o processo de urbanização se acelerava, outros elementos se combinaram para que o descolamento do parto da casa para o hospital pudesse se efetivar: após as duas Guerras Mundiais, foram aperfeiçoadas técnicas e

8 Como se sabe, as parteiras não desapareceram, apenas foram submetidas à autoridade médica e às novas regras de atuação que passaram a vigorar no século XIX, na Europa e nas colônias. De acordo com Ferreira (2019), as parteiras foram incluídas de forma "perversa" no campo da obstetrícia, subalternizadas por um Estado violento e vigilante dos corpos femininos. Para elas, o parto seria uma travessia pessoal e comunitária, que alia fisiologia, espiritualidade e processos subjetivos e ancestrais profundos. No Brasil atualmente existem cerca de 60 mil parteiras tradicionais em atividade, principalmente nas regiões mais distantes de centros urbanos, no Norte e no Nordeste (Ferreira, 2019, p. 41). 
instrumentos cirúrgicos, ampliou-se o número de instalações hospitalares e de maternidades, os meios de comunicação passaram a valorizar a novidade do parto hospitalar (considerado mais "civilizado"), a indústria farmacêutica expandiu-se e novas tecnologias e equipamentos de diagnóstico foram desenvolvidos (Mott, 2002; Nagahama; Santiago, 2005). Desse modo, cristalizavam-se o protagonismo do médico e a legitimidade social da obstetrícia, ao passo que as mulheres eram excluídas da produção do conhecimento autorizado num campo que tradicionalmente dominavam. Mas importa sublinhar que, no Brasil, somente na década de 1970 a maioria dos partos passou a ser realizada no hospital.

Porém tal processo de medicalização não produziu efeitos homogêneos para o conjunto das mulheres brasileiras. Com efeito, Mott (2002) e Palharini e Figuerôa (2018) demonstram que as mulheres pobres foram usadas como cobaias para o desenvolvimento de novas tecnologias obstétricas, sendo que as inovações e melhorias no atendimento assim obtidas eram reservadas para as mulheres brancas da elite.

Em meados do século XX, o modelo obstétrico tecnocrático consolidou-se nos Estados Unidos e tornou-se referência internacional. De acordo com Martin (2006), a cesariana passou então a ser percebida pelos médicos como o processo que forneceria os melhores produtos, representando a máxima intervenção médica em contraste com a mínima participação da mulher. O estabelecimento de um tempo máximo de gestação (40 semanas) e um tempo máximo para o trabalho de parto ( 12 horas $)^{9}$ associava-se diretamente à atitude de depreciação e repúdio ao corpo da mulher, expressão prática do controle que os médicos assumiam sobre esse corpo e sobre o parto.

Paralelamente, ampliavam-se as críticas, as dissidências e as estratégias de resistência em relação ao parto tecnocrático, todas elas buscando, de maneiras diferentes, desequilibrar as relações de poder em favor das mulheres e dos saberes "tradicionais" ou "alternativos". Nos anos 1950 os médicos Fernand Lamaze e Grantly Dick-Read difundiram o modelo do parto sem dor, e nos

9 A relevância da duração do trabalho de parto no âmbito do modelo tecnocrático pode ser aferida, por exemplo, por meio de uma notícia recente: em julho de 2020, um hospital em São Paulo foi criticado por ativistas da humanização por cobrar uma taxa equivalente a quase dois salários mínimos a mulheres que demorassem mais de seis horas para parir (Balogh, 2020). 
anos 1970 os médicos Frédérick Leboyer e Michel Odent e a antropóloga Sheila Kitzinger difundiram o modelo do parto sem violência. Nos anos 1980 a educadora perinatal inglesa Janet Balaska iniciou o movimento do parto ativo e desde então foram construídos centros de parto ativo em vários países. Nos anos 1990, na Europa e nos Estados Unidos algumas parteiras e doulas, como Ina May Gaskin, Elizabeth Davis e Debra Pascali-Bonaro, começaram a popularizar a experiência do parto orgástico, associado ao prazer, ao erotismo e à alegria, que contrasta de forma forte com a imagem cristã do parto, que evoca o sofrimento, o sacrifício e a dor.

No Brasil, nos anos 1980, os modelos do parto sem dor, do parto sem violência e do parto ativo, combinados a ideais e princípios inspirados no movimento da contracultura, no naturalismo, na Nova Era e no ecofeminismo, que circulavam na cena internacional desde os anos 1960, se desdobraram no multifacetado movimento de humanização do parto e nascimento, formado por mulheres de classe média, médicos, enfermeiras, parteiras e doulas. ${ }^{10} \mathrm{O}$ principal objetivo do movimento era positivar as experiências de gestar e parir, geralmente recorrendo à noção de perfeição do corpo feminino e investindo na associação entre parto, sexualidade e transcendência. Para Bellón Sánchez (2015), em vários países as ativistas têm gerado múltiplas estratégias discursivas em torno do conceito de "parto natural" à luz das mudanças dos significados associados aos termos relacionados ao parto; além disso, ela pensa que as reivindicações pelo parto respeitoso problematizam não apenas a qualidade da atenção ao parto, mas também os cimentos teóricos nos quais o modelo biomédico hegemônico se baseia.

Já no final do século XX, profissionais de saúde e pesquisadores começaram a alertar os órgãos de saúde e a população em geral sobre os riscos envolvidos no processo de medicalização e patologização da gestação e do parto, de modo que, em 1985, a Organização Mundial da Saúde publicou o importante documento Appropriate technology for birth (World Health Organization, 1985),

10 Picheth, Crubellate e Verdu (2018) mostram que o movimento de humanização do parto e nascimento consiste em uma constelação heterogênea de atores públicos e privados que se situam em diferentes campos. Compondo múltiplas parcerias institucionais e políticas para elaborar e implementar políticas públicas específicas, tais atores operam local e transnacionalmente, desvelando uma espiral complexa de autorreforço marcada por interdependências e emaranhamentos, o que gera inovações e efeitos contra-hegemônicos sistêmicos. 
no qual foram consignadas recomendações que visavam a restringir as intervenções médicas, sobretudo a cesariana, devido a seus efeitos comprovadamente danosos. ${ }^{11}$

Na mesma época, ampliava-se a consciência sobre a iniquidade de gênero e a pauta dos direitos sexuais e reprodutivos ganhava corpo no cenário internacional, dando ensejo a grandes conferências e a importantes documentos. O movimento feminista brasileiro, amparado pela Constituição Cidadã, colocava em pauta a questão das variadas violências contra a mulher, que desde então passaram a ser devidamente nomeadas e desprivatizadas. ${ }^{12}$ No momento em que o ajuste estrutural aplicado pelo Fundo Monetário Internacional (FMI) exigia a redução do crescimento demográfico brasileiro, foi promulgada a lei federal sobre planejamento familiar (Lei nº 9.263/1996 [Brasil, 1996]) e aumentavam as taxas de esterilização feminina via laqueadura, então utilizada como método contraceptivo, sendo que muitas vezes o procedimento era realizado durante a cesariana, a despeito dos riscos para a saúde da mulher. ${ }^{13}$ Apenas nos anos 1990 a Organização Pan-Americana de Saúde (OPAS) e a OMS reconheceram os impactos da violência de gênero sobre a saúde pública, com destaque para o aborto inseguro e as taxas de morte materna (Scavone, 2004).

No Brasil, o século XX se encerrou com a constatação do paradoxo perinatal, ou seja, verificavam-se a melhora de praticamente todos os indicadores de saúde materna e a ampliação do acesso aos serviços de saúde, no entanto as taxas de mortalidade materna continuavam altas (Diniz, 2009). Assim,

11 Outrossim, como nos apontaram algumas doulas, a ênfase na mera redução estatística das taxas de cesariana pode encobrir o aumento de intervenções violentas, tais como episiotomia, aplicação de ocitocina sintética e manobra de Kristeller, praticadas com o objetivo de acelerar o trabalho de parto por via vaginal.

12 Ferreira (2019, p. 56) sublinha a importância da realização de novas pesquisas sobre as correlações entre violência obstétrica, mortes maternas, aborto, violência sexual e feminicídio, pois “os países da América Latina possuem as legislações mais restritivas com relação ao aborto, os maiores índices de mortalidade materna e neonatal, os piores cenários de violência obstétrica do mundo e uma enorme tolerância social diante destas violências."

13 Porém cabe citar um contraponto etnográfico: de acordo com Dalsgaard (2006), nos últimos anos do século XX, mulheres pobres que habitavam a região metropolitana de Recife e tentavam conseguir a esterilização como recurso contraceptivo, na esperança de exercer controle sobre a própria vida, enfrentavam toda sorte de dificuldades colocadas pelos médicos. A autora tece considerações riquíssimas sobre a articulação tensa entre planejamento familiar e controle populacional governamental em um contexto local frequentemente caracterizado pelo estereótipo da mãe pobre morrendo de fome. 
enquanto a cobertura dos serviços se ampliava, o foco das atenções da sociedade civil foi se deslocando para a qualidade desses serviços - e a essa mudança de foco parecem corresponder tanto a emergência da categoria violência obstétrica como o agenciamento crescente do conceito de justiça reprodutiva.

\section{Pelo direito a narrar a violência obstétrica}

A partir de uma pesquisa realizada com profissionais de saúde atuando no estado de São Paulo no início do século XXI, Aguiar, d’Oliveira e Diniz (2020, p. 138) afirmam que o modelo intervencionista de assistência ao parto se sustenta porque converge com interesses diversos, mas também por seu caráter ritual e por sua capacidade de reproduzir valores e relações sociais. A persistência de crenças, valores e imagens compartilhados relativos ao parto e ao corpo feminino, delineados no século XIX e estabilizados no século XX, como apresentado anteriormente, é de fato impressionante.

Ocorre que, nas duas últimas décadas, com a popularização da internet no Brasil e na América Latina, muitas mulheres passaram a divulgar imagens e relatos de parto em primeira pessoa, incluindo a experiência do parto domiciliar planejado, registrados em textos, fotos e vídeos (Tempesta, 2018). Esse compartilhamento de experiências positivas e negativas, realizado por mulheres com alto nível de escolaridade, por vezes incorporava resultados de pesquisas realizadas sob o paradigma da medicina baseada em evidências (MBE), um movimento nascido no âmbito da epidemiologia anglo-saxônica nos anos 1990, que se utiliza de ensaios clínicos randomizados para identificar tendências (mais do que padrões) em processos de saúde-doença.

No que se refere a gestação e parto, vários médicos "dissidentes", enfermeiras obstétricas e doulas passaram a replicar nas redes sociais dados atualizados providos pela $\mathrm{MBE}$, obtidos na Plataforma Cochrane, ${ }^{14}$ para fundamentar denúncias de que grande parte dos procedimentos de rotina utilizados nos

14 Esta é uma iniciativa internacional que reúne um grande número de pesquisadores, cuidadores, gestores e financiadores da área da saúde de diversos países, com acesso gratuito e livre (https://www.cochranelibrary.com/). Na plataforma há artigos que comprovam, por meio de indicadores específicos, os benefícios do apoio contínuo provido pela doula. Existe também a versão brasileira: https://brazil.cochrane.org. 
hospitais carece de fundamento científico, sendo que vários deles não apenas não trazem qualquer benefício para a mulher ou o feto como podem inclusive trazer malefícios mais ou menos graves para ambos. Nesse período, o compartilhamento de tais relatos e também de dados científicos atualizados abriu um espaço de debate público que vem se alargando, no qual se gestou algum grau de consciência crítica, o que tem permitido explicitar e desnaturalizar um amplo conjunto de abusos, agressões e negligências característicos do modelo obstétrico tecnocrático. ${ }^{15}$

O debate deu ensejo à realização de pesquisas de amplo escopo, cujos resultados por vezes são apropriados pelas doulas e por ativistas da humanização do parto. Em 2010, a Fundação Perseu Abramo, em parceria com o Sesc-SP, realizou uma pesquisa de opinião pública chamada "Mulheres brasileiras nos espaços público e privado", que concluiu o seguinte: uma em cada quatro mulheres brasileiras que deram à luz em hospitais públicos ou privados relatou ter sofrido algum tipo de agressão durante o parto; mulheres de todas as camadas sociais e pertencimentos étnicos-raciais estão sujeitas a sofrer violência obstétrica, porém as modalidades de violência variam bastante a depender da articulação contingencial dos marcadores sociais da diferença; mulheres muito jovens, negras e pobres têm mais chances de morrer durante a gestação, trabalho de parto e pós-parto; uma das frases mais ouvidas pelas entrevistadas foi: "Na hora de fazer você não chorou/não chamou a mamãe, por que está chorando/chamando agora?" (Venturi; Godinho, 2013).

Entre 2011 e 2012 uma equipe de pesquisadores vinculados à Fiocruz realizou um amplo inquérito nacional, abrangendo instituições públicas e privadas, chamado "Nascer no Brasil". As informações obtidas subsidiaram a elaboração de dezenas de artigos acadêmicos, porém a conclusão mais relevante para a presente argumentação consiste na identificação do potencial iatrogênico da assistência, presente de forma mais explícita em procedimentos como episiotomia de rotina, aplicação de ocitocina de rotina e cesariana eletiva, que predominam na rede particular, e negligência durante o pré-natal e indisponibilidade

15 Pulhez (2013) analisou a questão da violência obstétrica a partir do conceito de vocalização de traumas decorrentes de violações de direitos humanos. Contudo, cabe mencionar a crítica que feministas como Crenshaw (2002) tecem à limitação desse paradigma, que fundamenta os tratados internacionais, sobretudo em termos do não reconhecimento dos efeitos interativos das distintas formas de discriminação. 
de analgesia durante o trabalho de parto, sobretudo na rede pública (Ferreira, 2019; Leal et al., 2017).

Considerando que em nossa cultura prevalece uma imagem pessimista do parto vaginal, entendido como evento arriscado, associada à ideia de que o corpo feminino não está preparado para parir, que dá ensejo ao medo compartilhado por muitas mulheres e profissionais de saúde, percebe-se como a indução e a cesariana surgem como dispositivos para racionalizar o tempo dos profissionais, em consonância com a cultura institucional predominante, de modo que a um só tempo incrementam-se os lucros do hospital e se reafirma a perspectiva de uma assistência "mais moderna", entendida como progresso científico, em detrimento da dimensão relacional (Aguiar; d'Oliveira; Diniz, 2020, p. 141).

Também em outros países da América Latina a crítica ao modelo hegemônico de atenção obstétrica se fortaleceu nas últimas décadas, e desde o ano de 2007 a expressão "violência obstétrica" - que alcança o estatuto de contestação epistêmica (cf. Sesia, 2020) - tem sido incorporada a vários ordenamentos jurídicos. ${ }^{16}$ Em muitos países a mobilização social e as pesquisas acadêmicas vêm se ampliando. Atualmente existem diversos Observatórios da Violência Obstétrica (OVOs), ONGs e coletivos que organizam marchas e se fazem presentes com força nas redes sociais, ativistas que realizam mostras artísticas e documentários independentes, além de doulas que conduzem rodas de parto e pós-parto em diversos locais, de modo que os meios de comunicação alternativos e a grande mídia têm se interessado por esse debate.

O tema da violência obstétrica mereceu inclusive a elaboração de um relatório abrangente, encomendado pela Organização das Nações Unidas (ONU) em 2019, que subsidiou um conjunto de recomendações para os países-membros, dentre as quais destacamos a importância do consentimento livre e informado prévio às intervenções médicas (United Nations, 2019).

16 2007: México, Ley General de Acceso de las Mujeres a una Vida Libre de Violencia (México, 2007, art. 6); 2007: Venezuela, Lei Orgánica sobre el Derecho de las Mujeres a una Vida Libre de Violencia (Venezuela, 2007, art. 15); 2009: Argentina, Lei 26.485 (Argentina, 2009, art. 6); 2013: Bolívia, Ley Integral para Garantizar a las Mujeres una Vida Libre de Violencia (Bolivia, 2013, art. 7 - inclusão da expressão "violência contra os direitos reprodutivos" em 2018); 2013: Panamá, Lei 82 (Panamá, 2013, art. 4); 2014: Brasil, PL nº 7.633/2014 (Brasil, 2014) - ao qual foram anexados os PLs n 7.867/2017 (Brasil, 2017a) e n 8.219/2017 (Brasil, 2017b) -, ainda em tramitação. 
Na pesquisa de campo que realizamos e em muitos dos textos aqui citados, evidencia-se uma correlação entre violência obstétrica e as altas taxas de morbimortalidade materna e neonatal observadas no Brasil e na América Latina. Ao passo que os Objetivos de Desenvolvimento Sustentável para 2030 estabelecem como meta o número de 30 mortes para cada 100 mil nascidos vivos, no Brasil, em 2017 ocorreram 65 mortes para cada 100 mil nascidos vivos. A maioria dessas mortes se deve a causas evitáveis, estando diretamente associadas à qualidade da assistência perinatal. ${ }^{17}$ Quando se desagregam os dados da razão da mortalidade materna por raça/cor e escolaridade, constata-se que as mulheres pretas e pardas com menores níveis de escolaridade têm muito mais chances de morrer no parto, em comparação com as mulheres brancas com maiores níveis de escolaridade. Além da morte, as mulheres estão sujeitas a uma série de outros problemas de saúde diretamente associados ao parto, como a depressão pós-parto. Cabe sublinhar que, apesar de resultarem da articulação de diversas violências, os dados oficiais sobre morte materna são em geral apresentados separadamente (Ferreira, 2019, p. 141).

Quando se considera que, atualmente, no Brasil, cerca de 98\% dos partos acontecem em ambiente hospitalar, ${ }^{18}$ podemos perceber a magnitude do problema social delineado a partir dos números e informações supracitados.

Ferreira (2019) afirma que a violência obstétrica se beneficia da impunidade dos médicos, embora reconheça algumas conquistas jurídicas resultantes de alianças estabelecidas entre ativistas, membros do Ministério Público Federal e defensores públicos nos estados e municípios. Ela enfatiza que raramente as mulheres formalizam denúncias de violência obstétrica e chama a atenção para o fato de que as normativas em vigor ainda têm um estatuto infralegal. A nosso ver, tal “indeterminação normativa” (cf. Segato, 2016) seria um aspecto

17 Como explicita o documentário Evitável (2019), que traz relatos sobre a morte de três mulheres jovens, pertencentes à camada popular, no estado de Pernambuco; uma delas morreu em decorrência de um abortamento e as outras duas, após o parto. Da narrativa, depreende-se que as três mortes resultaram de negligência médica.

18 Ferreira (2019) argumenta que, em lugares remotos, o Estado não oferece assistência ao parto, apenas vigia de longe o que se passa - afirmação que parece ser confirmada, por exemplo, pela etnografia realizada por Fleischer (2010) no Pará. Outrossim, merece atenção o modelo das casas de parto normal, instituições públicas nas quais a assistência é prestada por enfermeiras obstétricas. 
funcional do sistema patriarcal, que silencia esta e muitas outras formas de violência contra as mulheres.

De acordo com a crítica contundente formulada por Ferreira (2019), a proposta da humanização do parto não ofereceria uma base epistemológica que possa efetivamente superar o modelo obstétrico hegemônico, uma vez que a episteme da $\mathrm{MBE}$, principal pilar da humanização, permaneceria vinculada às concepções da razão cientificista e da prática médica como uma disciplina das biociências, portanto seguiria sendo fundamentalmente uma prática de controle misógina, racista e classista (Ferreira, 2019, p. 107-110).

Embora essa crítica nos pareça indispensável, gostaríamos de ponderar que, quando nos debruçamos sobre a expressão pública atual do movimento - as audiências públicas, lives nas redes sociais, manifestações de rua, notas públicas, documentários de circulação livre, grande número de pesquisas acadêmicas, além da crescente atuação de mulheres negras e periféricas em torno da reivindicação de um parto respeitoso -, percebemos efeitos políticos e subjetivos capazes de fazer frente, em alguma medida, à articulação de opressões que perpassa a violência obstétrica.

Entendemos que a denúncia da persistência da utilização de procedimentos obstétricos não respaldados em evidências científicas atualizadas ou de procedimentos não recomendados pela OMS, veiculada por médicos "dissidentes", enfermeiras obstétricas e doulas nos círculos do parto humanizado, aponta para uma expressão particular da articulação entre a misoginia constitutiva da obstetrícia e o racismo estrutural, em consonância com aquilo que Lima (2018, p. 23) chama de uma "bionecropolítica à brasileira". Adaptando a leitura crítica que o filósofo camaronês Achille Mbembe faz dos conceitos de biopoder e biopolítica elaborados por Michel Foucault ao contexto brasileiro, a autora cunhou esse conceito híbrido para se referir a uma configuração política e subjetiva que se assenta sobre o "conjunto semiótico" constituído pelo mito da democracia racial, pelo imperativo da miscigenação e pelo projeto de embranquecimento da população.

Se analisarmos os resultados das pesquisas supracitadas à luz do conceito de bionecropolítica à brasileira, considerando o contexto das hierarquias reprodutivas engendradas no período escravocrata, perceberemos o delineamento de alguns pressupostos culturais de longa duração, tais como: mulheres negras são mais "fortes" (ou seja, teriam maior tolerância à dor, logo não precisariam 
de anestesia, por exemplo), mulheres brancas das classes média e alta não devem ter o corpo "estragado" pelo parto (daí a necessidade de recorrer a tecnologias preventivas ou reparadoras do ponto de vista estético, como a episiotomia e a cesariana), mulheres pobres têm filhos "demais", mulheres com deficiência não deveriam ter filhos, dentre outros. Assim, constatamos que, se todas as mulheres estão sujeitas a sofrer violência durante o ciclo gravídico-puerperal, são as mulheres racializadas, pobres ou com deficiência as que têm as maiores chances de perder a vida e/ou de perder seu bebê - como bem sabem as doulas.

Ao tomar a atitude de explicitar e problematizar essas ações violentas e negligências, as ativistas do parto respeitoso e as doulas atraíram a oposição de grande parte da corporação médica, como fica patente na emissão do Parecer CFM n ${ }^{\circ} 32 / 2018$ pelo Conselho Federal de Medicina (CFM), em outubro de 2018, no contexto das eleições gerais que levariam ao poder grande número de candidatos da ala conservadora. Esse documento resume a posição da entidade, enfaticamente contrária à edição de leis que dispõem sobre violência obstétrica, ${ }^{19}$ e assenta que "a expressão 'violência obstétrica' tem produzido grande indignação entre os obstetras, pois seu uso tem se voltado em desfavor da nossa especialidade, impregnada de uma agressividade que beira a histeria, e responsabilizando somente os médicos por todo ato que possa indicar violência ou discriminação contra a mulher" (Conselho Federal de Medicina, 2018, p. 2, grifo nosso).

Na sequência, em maio de 2019, o Ministério da Saúde editou um despacho que determinava a supressão da expressão "violência obstétrica" dos textos das políticas públicas, devido ao seu caráter "ideológico"; esse documento estabelece que a expressão possui "conotação inadequada, não agrega valor e prejudica a busca do cuidado humanizado no continuum gestação-parto-puerpério" (Brasil, 2019a). Todavia, no mês de junho subsequente, após a expedição de uma recomendação pelo Ministério Público Federal, que resultou de tratativas

19 Diante da demora na tramitação do PL nº 7.633/2014 (Brasil, 2014) na esfera federal, entre 2017 e 2018 foram publicadas as seguintes leis estaduais sobre violência obstétrica: Santa Catarina, Lei $n^{\circ}$ 17.097/2017 (Santa Catarina, 2017); Distrito Federal, Lei ${ }^{\circ}$ 6.144/2018 (Distrito Federal, 2018); Minas Gerais, Lei $n^{\circ}$ 23.175/2018 (Minas Gerais, 2018); Pernambuco, Lei $n^{\circ} 16.499 / 2018$ (Pernambuco, 2018); e Mato Grosso do Sul, Lei n5.217/2018 (Mato Grosso do Sul, 2018). Porém tais leis têm um caráter predominantemente informativo e não estipulam tipificação penal. 
feitas pelas ativistas, o Ministério da Saúde publicou o Ofício $n^{\circ}$ 296/2019 (Brasil, 2019b), no qual reconheceu "o direito legítimo" das mulheres a usarem o termo sem, contudo, abolir a orientação para que não seja utilizado em documentos oficiais.

Pouco antes, no mês de abril de 2019, uma deputada da ala conservadora apresentara na Assembleia Legislativa de São Paulo o Projeto de Lei ${ }^{\circ}$ 435/2019 (que ficou conhecido como "PL das cesáreas"), que "garante à gestante a possibilidade de optar pelo parto cesariano, a partir da $39^{\mathrm{a}}$ semana de gestação, bem como a analgesia, mesmo quando escolhido o parto normal" (São Paulo, 2019a). O PL tramitou em regime de urgência e, depois de apenas quatro meses, transformou-se na Lei $n^{\circ}$ 17.137/2019 (São Paulo, 2019b). O texto do PL foi replicado em vários outros estados, sem que tivesse sido realizado um debate mais aprofundado sobre a matéria. Porém, as ativistas mais uma vez se articularam e, em julho de 2020, o Tribunal de Justiça de São Paulo decidiu pela inconstitucionalidade da lei.

Nas audiências públicas realizadas para debater o referido projeto de lei, os defensores da proposta apelaram para a ideia de direito individual da parturiente a não sofrer ou a não sentir dor. Nessa perspectiva, as diversas intervenções (episiotomia, manobra de Kristeller, cesárea eletiva) são justificadas pelo princípio da beneficência (França, 2020). Mas o que tal proposição oblitera é o fato, demonstrado pelas pesquisas supracitadas, de que a dor e o sofrimento são na maioria das vezes causados pela própria assistência, bem como pela falta de acesso a informações sobre direitos e sobre os efeitos nocivos de certas práticas de rotina e a alternativas para alívio da dor, como as oferecidas pelas doulas. Deparamo-nos aqui com os sérios limites da ideia de "escolha consciente e informada", correlata das noções de "autonomia" e "protagonismo", que têm todas uma base liberal.

Se a percepção geral do parto normal é a de um evento arriscado e imprevisível, a cirurgia cesariana aparece como possibilidade de um parto seguro, controlado e indolor, além de carregar um distintivo de classe. Complementarmente, a oferta formal de anestesia e cesariana, travestida em um direito individual, esvazia o conteúdo público da discussão sobre o modelo de assistência obstétrica, joga com imagens de "civilização" e arcaísmo e indica a possibilidade de uma solução supostamente rápida e pontual para um problema que, como demonstramos, é sistêmico e multifacetado. 
No entanto, durante uma audiência pública sobre o enfrentamento à violência obstétrica no Brasil realizada na Câmara Federal, no dia 2 de julho de 2019, uma doula ponderou que as mulheres mais pobres têm menos condições de guardar o repouso que uma cirurgia como a cesariana exige, pois, por vezes, essas mulheres são as únicas responsáveis pelos serviços domésticos e pelos cuidados com filhos, podendo ainda ser as principais responsáveis pela renda familiar. Desse modo, a cesariana eletiva seria uma prática fundamentalmente excludente. No entanto, foi levantado que a procura pela cesariana muitas vezes deriva do medo de sofrer as violências geralmente associadas ao parto vaginal.

No dia 3 de setembro de 2019 ocorreu outra audiência pública na Câmara Federal, dessa vez para discutir o PL $n^{\circ} 3635 / 2019$ (Brasil, 2019c), que consiste na replicação do "PL da cesárea" em nível federal. Diversas falas ressaltaram a impropriedade de entender como expressão de autonomia da mulher uma escolha que se faz em circunstâncias de precariedade institucional, atendimento não baseado em evidências científicas atualizadas e ausência de alternativas para amenizar a dor e o desconforto no trabalho de parto. A professora de obstetrícia convidada resumiu a impressão de muitas ativistas e profissionais humanizados: "Quando a mulher pede por uma cesárea, ela está pedindo para que não a deixem sofrer uma violência durante o parto."

Assim, por meio de uma torção semântica, o parto vaginal acaba se tornando sinônimo de violência obstétrica no imaginário popular, entendido como a regra na rede pública, e a cesariana, associada à assistência privada, é apresentada como uma forma de escapar a essa violência.

A abordagem fenomenológica da violência obstétrica pode agregar elementos relevantes para a reflexão. A filósofa Sara Cohen Shabot (2016) indica que o ideal de passividade dos corpos é constitutivo da medicina moderna, que ainda toma o cadáver como referente epistemológico, de modo que os corpos barulhentos, em movimento, criativos e potentes - mas também vulneráveis ${ }^{20}$ - são alvo de práticas de domesticação violentas.

20 Nos círculos humanizados é comum ouvir referências à "partolândia", um estado de consciência ímpar no qual a mulher teria acesso a outras dimensões da experiência, porém ficaria especialmente vulnerável às ações de terceiros. 
Para ela, o trabalho de parto seria uma das poucas oportunidades que as mulheres ocidentais teriam de experimentar uma situação de subjetividade através da corporalidade, uma situação em que elas não estão alienadas de seu corpo, mas sim profundamente identificadas com ele - uma experiência integrativa, em suma. A experiência de parto daria ensejo à expansão da restrita zona de liberdade corporal reservada às mulheres pelo patriarcado, uma atitude de recusa rebelde ao papel social imposto às mulheres. Como medida de restringir coercitivamente essa atitude insubmissa, a autora propõe que o birth rape ("parto-estupro") configuraria uma forma radical de "colocar as mulheres em seu lugar", isto é, no lugar do silêncio e da passividade. Parece delinear-se aqui uma verdadeira pedagogia da violência que se impõe às mulheres, pois seria necessário ensinar os corpos a parir de forma dolorosa e contida. ${ }^{21}$ Todavia, sabemos que, no terreno da empiria, essa pedagogia genérica atinge diferencialmente as mulheres, a depender da posição que ocupam na hierarquia reprodutiva vigente em cada contexto; ademais, cabe fazer a ressalva de que essa potência do self se exprime de formas diversas em corpos distintos.

Shabot (2016) acredita no potencial da criação de espaços de discussão e reflexão que levem a mudanças reais, no sentido de possibilitar uma experiência de parto e sobretudo uma vida digna para as mulheres. Essa proposta converge com as ideias de Segato (2016), que defende que princípios e valores subjacentes a práticas violentas sejam expostos e examinados publicamente, com a participação dos sujeitos a elas submetidos. Como veremos, as doulas e educadoras perinatais têm contribuído para a criação de espaços desse tipo, voltados à construção de condições objetivas para o desenvolvimento de um diálogo simétrico, seguro e profícuo sobre reprodução, visando ao estabelecimento de pactos culturais mais justos e benéficos para o conjunto da sociedade.

21 De forma semelhante, Ferreira (2019) afirma que o processo de medicalização do parto deu ensejo a um padrão de "parto disciplinado" que supõe a violência. Nesse sentido, a violência obstétrica seria uma forma de punição da sexualidade feminina, provendo a inscrição física e psíquica do lugar de pertencimento e das possibilidades de existência na mulher e no bebê, conforme seus marcadores sociais da diferença. 


\section{Uma pedagogia reprodutiva contra-hegemônica}

As doulas e educadoras perinatais acompanham mulheres de perfis muito diversos, em situações reprodutivas distintas e em cenas variadas. Doulas não são parteiras, embora o papel social que desempenham na atualidade evoque tacitamente aquele arranjo cultural que não se centra na figura do médico ou no hospital, e no qual gestação e parto não são sinônimos de patologia. É preciso ter em mente que o leque de estilos de atuação das doulas é bastante diversificado, assim como são variados os seus posicionamentos políticos (Tempesta, 2018). No entanto, de um modo geral, as doulas problematizam aspectos do ciclo gravídico-puerperal que são naturalizados e se encontram cristalizados em pressupostos culturais que permeiam toda a sociedade e adquirem uma face cientificista no campo do saber-poder obstétrico.

As doulas utilizam um conjunto de objetos e imagens não convencionais para simular os eventos fisiológicos associados à reprodução, tais como balão de borracha, bola de fisioterapia, seios de crochê, etc. Muitas doulas alinhadas à medicina baseada em evidências científicas insistem no valor da informação qualificada para a pessoa gestante, defendem o respeito à fisiologia do parto, afirmam utilizar tecnologias "leves" e adotar uma abordagem integral do ciclo gravídico-puerperal, primando pelo protagonismo da mulher na cena de parto e pelo seu bem-estar geral ao longo de todo o processo.

Além da participação na cena do parto, doulas também conduzem, nos mais variados locais, rodas de conversa com pessoas gestantes e puérperas; esses são espaços seguros e não hierárquicos de escuta empática e respeitosa, de troca de informações confiáveis e de compartilhamento de sentimentos e experiências pessoais, que se constituem como uma ferramenta pedagógica importante, um contraponto incisivo à pedagogia da dor e da contenção que se manifesta na violência obstétrica.

Em entrevista concedida a uma de nós em 2018, a doula negra Sharon (pseudônimo) relatou o seguinte:

[...] quando há alguma complicação no parto, as mulheres brancas não têm muito: "Será que a gente vai levar essa mulher pra cesárea?" Não, aconteceu uma complicação: "Vamos levá-la para a cesárea!", não tem o que discutir. Normalmente as mulheres negras ficam ali mais tempo. Então, tipo: "Ah, tá tendo uma 
complicação, mas..." Há essa ideia de que a mulher negra é mais forte, de que ela é mais resistente à dor. [Além da negligência] tem outras questões também, que são bem específicas: eu sei que, se uma mulher tem um plano de saúde, no hospital X [particular], que tem uma estrutura muito melhor, tem um banheiro disponível, ela vai lá e vai tomar banho e vai ficar debaixo do chuveiro o tempo que ela quiser, muito possivelmente ela vai ter um quarto só pra ela, ela vai receber comida, sem ninguém questionar, na maioria das vezes, se ela tem que comer ou não, e uma comida boa, de qualidade. [...] Agora, se eu vou pro hospital Y [público], eu sei que essa mulher mal vai conseguir tomar água, e eu sei, baseada em evidências científicas, que ela precisa se alimentar e ela precisa tomar água durante o trabalho de parto, mas ela está indo pra um lugar que nega, então como é que a gente vai lidar com isso? Então a maneira de eu atender essa mulher já vai ser diferente; vou ter que dar uns toques pra ela: "Olha, leva uma comida, provavelmente eles não vão te oferecer comida lá, leva uma garrafa dágua." Conversar com a pessoa que vai acompanhar, também, nesse momento, como que ela vai lidar. Então o atendimento acaba sendo diferente mesmo, as informações em relação à instituição mudam muito, então essa questão da singularidade não tem como ser ignorada, mesmo que você esteja seguindo a mesma evidência científica, a experiência que essa mulher vai ter de parto vai ser muito diferente, muitas vezes por conta de questões financeiras ou questões de raça. [...]

O relato de Sharon se soma aos relatos de muitas outras doulas que acompanhamos. De um modo geral, nos atendimentos individualizados ao longo da gestação e nas rodas de conversa presenciais ou virtuais, elas costumam falar sobre a fisiologia do parto e as principais intercorrências; apresentam métodos não farmacológicos de alívio da dor; apoiam a redação do plano de parto; indicam fontes de informação confiáveis; ouvem as angústias e dúvidas da doulanda; atentam para a situação social da mulher, a fim de modular seu atendimento conforme os critérios que geralmente dão ensejo a tratamentos distintos nas instituições, como fica evidente no trecho transcrito acima.

É notório o empenho da profissional em criar uma forma de acolhimento respeitoso no interior de um local que se mostra hostil, no qual não há sequer comida e água disponíveis para mulheres em trabalho de parto. No interior desse espaço-tempo relacional criado pela doula, as necessidades, os desejos e o ritmo de cada mulher podem ser respeitados e também contemplados. $E$ isso 
se faz por meio da presença de espírito, da disposição para atentar aos detalhes, da percepção refinada e profunda a respeito daquilo que pode gerar bem-estar para a mulher.

Tais habilidades são adquiridas no processo de formação da doula, que, como descrevem Silva e Russo (2019), é eclético e implica uma transformação de dentro para fora, por meio de atividades de caráter "vivencial", privilegiando-se a expressão das emoções como forma de ajustá-las a uma nova relação com o corpo. Nos cursos de formação, a transmissão de conhecimentos sobre a identidade feminina e seus poderes reprodutivos se dá de forma personalizada e iniciática, combinando os conhecimentos obtidos nas vivências a práticas "tradicionais" e "alternativas" e também a informações providas pela medicina baseada em evidências científicas.

Além disso, algumas doulas se engajam em projetos comunitários que visam a promover a democratização do acesso à saúde, envolvendo pessoas em situação de maior vulnerabilidade social, tais como o Doulas Comunitárias (vinculado ao Hospital Sofia Feldman, em Belo Horizonte) e o Doula a Quem Quiser (uma iniciativa da associação de doulas do Rio de Janeiro voltada a mulheres privadas de liberdade) (Fernandes, 2019).

Doulas também produzem conhecimento sistematizado sobre o seu ofício. A doula negra Morgana Eneile, que atua também como professora em um curso público de formação de doulas, utiliza o conceito de racismo obstétrico elaborado pela antropóloga norte-americana Dána-Ain Davis (2019) para ampliar a reflexão sobre violência obstétrica no Brasil. Para ela,

se todas as mulheres são passíveis de serem violentadas no parto, há na pele uma diferenciação objetiva: mulheres negras morrem em consequência do fato de gestar e parir. E esse dado segue acompanhado de recortes territoriais e de acesso à educação e em informação em saúde. [...] Em regiões afastadas das zonas centrais, mulheres negras recebem menos analgesia e têm menos acesso a cirurgias cesarianas necessárias, por exemplo. (Eneile, 2020, p. 15-16).

Propomos que a combinação dessas facetas da doulagem e da educação perinatal, especialmente o repertório diversificado e heteróclito de saberes e práticas em torno do gestar e do parir agenciado por essas profissionais, converge com a atitude de to reclaim habilitada pela filósofa Isabelle Stengers (2018). Esse 
é um verbo cujo campo semântico abrange os sentidos de reivindicar, recuperar e atualizar certas práticas marginalizadas, desqualificadas e banidas pelo mundo moderno-capitalista, como a magia, a feitiçaria e o animismo. A autora explica que tal atitude não implica resgatar algo do passado nem se apropriar de algo inteiramente exógeno, mas compõe uma possibilidade de resistência ("afirmar uma existência") e de criação de novos possíveis, por meio de um trabalho de experimentação ativa, sempre aberto ao imponderável e ao imprevisível.

A partir desse repertório e da reflexão crítica sobre parto no Brasil e em outros países, muitas doulas e educadoras perinatais têm contribuído para o delineamento de um horizonte de justiça reprodutiva, criando um "ruído" importante no entremeio dos campos da saúde e do direito, que é recebido por grande parte da categoria médica como uma mensagem estridente ou "histérica", como consta explicitamente no supracitado parecer produzido pelo CFM em 2018.

\section{Considerações finais}

Em meio a um cenário nacional e internacional marcado pela intensificação do projeto neoliberal, pela ofensiva conservadora generalizada contra os direitos humanos e pela precarização dos sistemas de saúde públicos, constatamos que as questões afetas à reprodução adquirem uma importância ainda maior.

Em nossa busca por situar histórica e sociologicamente o conjunto de práticas, ideias e valores relativo ao parto enraizado em nossa cultura, percebemos que o modelo obstétrico tecnocrático oblitera os aspectos misteriosos, imprevisíveis e relacionais da vida, da morte, da dor, do prazer e da potência humana, e se utiliza de uma pedagogia da violência para domesticar e disciplinar as experiências reprodutivas, produzindo padrões rígidos e reproduzindo estereótipos que aprofundam opressões. Por outro lado, a doulagem emerge como uma tecnologia leve, de baixo custo, que corresponde a uma ética do cuidado na qual a saúde e o bem-estar da pessoa são centrais.

Associadas, doulagem e educação perinatal contribuem para a circulação de relatos e imagens que explicitam a multiplicidade das experiências de gestar e parir, contrapondo-se aos ou se apropriando criativamente dos padrões 
cientificistas hegemônicos, o que resulta em uma pedagogia reprodutiva contra-hegemônica. Doulas e educadoras perinatais dão uma contribuição decisiva para a conscientização a respeito da violência que atravessa as hierarquias reprodutivas vigentes, assim como convidam à valorização de outras dimensões envolvidas no gestar e no parir, propondo uma pedagogia respeitosa que pode favorecer a governança reprodutiva, por meio do aprofundamento da agenda da justiça reprodutiva no Brasil, quiçá em direção à criação de um novo "comum" no campo da reprodução.

\section{Referências}

AGUiAR, J. M. de; D'OliVEIRA, A. F. P.; DINIZ, C. S. G. El parto como "atropellamiento": ideologia médica, visión pessimista del parto normal y violencia obstétrica. In: QUATTROCCHI, P.; MAGNONE, N. (comp.). Violencia obstétrica em América Latina: conceptualización, experiencias, medición y estrategias. Remedios de Escalada: De la UNLa, Universidad Nacional de Lanús, 2020. p. 131-143.

ARGENTINA. Lei 26.485. Ley de proteção integral para prevenir, sancionar y erradicar la violencia contra las mujeres en los ámbitos en que desarrollen sus relaciones interpersonales. Buenos Aires: Congreso Argentino, 11 marzo 2009. Disponível em: https://www.oas.org/dil/esp/ley_de_proteccion_integral_de_mujeres_argentina.pdf. Acesso em: 20 jul. 2020.

BALOGH, G. Hospital cobra $R \$ 1.800$ de taxa para quem demorar mais de $6 \mathrm{~h}$ para parir. In: MÃES de peito. [S. l.]: Giovanna Balogh, 2 jul. 2020. Disponível em: http:// www.maesdepeito.com.br/hospital-cobra-r-1-800-de-taxa-para-quem-demorar-mais-de-6h-para-parir/ffbclid=IwAR33rIErYOhZBWgQxrukqzaUgYv61BAPtQu w9JhfGWqLIRlp0liuyrzo3zI. Acesso em: 9 jul. 2020.

BELLÓN SÁNCHEZ, S. La violencia obstétrica desde los aportes de la crítica feminista y la biopolítica. Dilemata, Madrid, año 7, n. 18, p. 93-111, 2015.

BIROLI, F. Gênero e desigualdades: limites da democracia no Brasil. São Paulo: Boitempo, 2018.

BOLIVIA. Ley Integral para Garantizar a las Mujeres una Vida Libre de Violencia. Ley 348. La Paz: Asamblea Legislativa Plurinacional, 9 marzo 2013. Disponível em: https://oig. cepal.org/sites/default/files/2013_bol_ley348.pdf. Acesso em: 20 jul. 2020. 
BRAH, A. Diferença, diversidade e diferenciação. Cadernos Pagu, Campinas, n. 26, p. 329-376, 2006.

BRASIL. Lei $n^{\circ}$ 9.263, de 12 de janeiro de 1996. Regula o $§ 7^{\circ}$ do art. 226 da Constituição Federal, que trata do planejamento familiar, estabelece penalidades e dá outras providências. Brasília: Presidência da República, 1996. Disponível em: https://www. planalto.gov.br/ccivil_03/leis/19263.htm. Acesso em: 20 jul. 2020.

BRASIL. Lei $n^{0} 11.108$, de 7 de abril de 2005. Altera a Lei $n^{\circ} 8.080$, de 19 de setembro de 1990, para garantir às parturientes o direito à presença de acompanhante durante o trabalho de parto, parto e pós-parto imediato, no âmbito do Sistema Único de Saúde - SUS. Brasília: Presidência da República, 2005. Disponível em: https://www.planalto.gov.br/ccivil_03/_ato2004-2006/2005/lei/111108.htm. Acesso em: 20 jul. 2020.

BRASIL. Projeto de Lei $n^{\circ}$ 7.633, de 2014 (Do Sr. Jean Wyllys). Dispõe sobre a humanização da assistência à mulher e ao neonato durante o ciclo gravídico-puerperal e dá outras providências. Brasília: Câmara dos Deputados, 27 maio 2014. Disponível em: https:// www.camara.leg.br/proposicoesWeb/prop_mostrarintegra;jsessionid=node0sitty qmx0ey3d3dg7ipowymj3632498.node0? codteor $=1257785$ \&filename $=\mathrm{PL}+7633 / 2014$. Acesso em: 20 jul. 2020.

BRASIL. Projeto de Lei $n^{\circ} 7.867$, de 2017 (Da Sra. Jô Moraes). Dispõe sobre medidas de proteção contra a violência obstétrica e de divulgação de boas práticas para a atenção à gravidez, parto, nascimento, abortamento e puerpério. Brasília: Câmara dos Deputados, 13 jun. 2017a. Disponível em: https://www.camara.leg.br/proposicoesWeb/prop_mostrarintegra;jsessionid=AC09E88E486EE2C6AC480F5277D5B CDB.proposicoesWebExternol ?codteor=1574562\&filename=Avulso+-PL+7867/2017. Acesso em: 20 jul. 2020.

BRASIL. Projeto de Lei $n^{\circ}$ 8.219, de 2017 (Do Sr. Francisco Floriano). Dispõe sobre a violência obstétrica praticada por médicos e/ou profissionais de saúde contra mulheres em trabalho de parto ou logo após. Brasília: Câmara dos Deputados, 9 ago. 2017b. Disponível em: https://www.camara.leg.br/proposicoesWeb/prop_mostrarintegra;js essionid=4ADB73DA542F580124833C8318C04384. proposicoesWebExterno2? codteor =1591466\&filename=Avulso+-PL+8219/2017. Acesso em: 20 jul. 2020.

BRASIL. Ministério da Saúde. Secretaria de Atenção à Saúde. Departamento de Ações Programáticas Estratégicas. Despacho DAPES/SAS/MS. Brasília: MS, 3 maio 2019a. Disponível em: https://sei.saude.gov.br/sei/controlador_externo.php?acao=documento_conferir\&codigo_verificador=9087621\&codigo_ crc=1A6F34C4\&hash_download=c4c55cd95ede706d0b729845a5d6481d07e735f33d8 7d40984dd1b39a32d870fe89dcf1014bc76a32d2a28d8f0a2c5ab928ff165c67d8219e35b ebla0adb3258\&visualizacao=1\&id_orgao_acesso_externo=0. Acesso em: 20 jul. 2020. 
BRASIL. Ministério da Saúde. Secretaria de atenção à saúde. Departamento de Ações Programáticas Estratégicas. Coordenação-Geral de Ciclos da Vida. Coordenação de Saúde das Mulheres. Ofício $n^{\circ}$ 296/2019/COSMU/CGCIVI/DAPES/SAPS/MS. Brasília: MS, 7 jun. 2019b. Disponível em http://www.mpf.mp.br/sp/sala-de-imprensa/docs/ oficio-ms. Acesso em: 20 jul. 2020.

BRASIL. Projeto de Lei $n^{0}$ 3.635, de 2019 (Dos Deputados Carla Zambelli, Alê Silva e Filipe Barros). Garante à gestante a possibilidade de optar pelo parto cesariano, a partir da trigésima nona semana de gestação, bem como a analgesia, mesmo quando escolhido o parto normal. Brasília: Câmara dos Deputados, 18 jun. 2019c. Disponível em: https://www.camara.leg.br/proposicoesWeb/prop_mostrarintegra?codteor=1766676. Acesso em: 20 jul. 2020.

CARNEIRO, R. G. De perto e de longe do que seria natural, mais natural e/ou humanizado. Uma etnografia de grupos de preparo para o parto. In: FERREIRA, J.; FLEISCHER, S. (org.). Etnografias em Serviços de Saúde. Rio de Janeiro: Garamond, 2014. p. 243-265.

CARNEIRO, R. G. Cenas de parto e políticas do corpo. Rio de Janeiro: Editora Fiocruz, 2015.

CONSELHO FEDERAL DE MEDICINA. Parecer CFM n 32/2018. A expressão “violência obstétrica" é uma agressão contra a medicina e especialidade de ginecologia e obstetrícia, contrariando conhecimentos científicos consagrados, reduzindo a segurança e a eficiência de uma boa prática assistencial e ética. Brasília: CFM, 23 out. 2018. Disponível em: https://sistemas.cfm.org.br/normas/visualizar/pareceres/ BR/2018/32. Acesso em: 20 jul. 2020.

CRENSHAW, K. Documento para o encontro de especialistas em aspectos da discriminação racial relativos ao gênero. Revista Estudos Feministas, Florianópolis, v. 10, n. 1, p. 171-189, 2002.

DALSGAARD, A. L. Vida e esperanças: esterilização feminina no Nordeste. São Paulo: Editora da Unesp, 2006.

DAVIS, A. Mulheres, raça e classe. São Paulo: Boitempo, 2016.

DAVIS, D.-A. Obstetric racism: the racial politics of pregnancy, labor, and birthing. Medical Anthropology, [s. l.], v. 38, n. 7, p. 560-573, 2019. DOI: https://doi.org/10.1080/0 1459740.2018.1549389.

DAVIS-FLOYD, R. The technocratic, humanistic, and holistic paradigms of childbirth. International Journal of Gynecology \& Obstetrics, [s. l.], n. 75, p. 5-23, 2001. 
DINIZ, C. S. G. Gênero, saúde materna e o paradoxo perinatal. Revista Brasileira de Crescimento e Desenvolvimento Humano, São Paulo, v. 19, n. 2, p. 313-326, 2009.

DINIZ, C. S. G. et al. Violência obstétrica como questão para a saúde pública no Brasil: origens, definições, tipologia, impactos sobre a saúde materna e propostas para sua prevenção. Jornal of Human Growth and Development, São Paulo, v. 25, n. 3, p. 377386, 2015.

DISTRITO FEDERAL. Lei $n^{\circ}$ 6.144, de 7 de junho de 2018. Dispõe sobre a implantação de medidas de informação a mulheres grávidas e paridas sobre a política nacional de atenção obstétrica e neonatal, visando, principalmente, à proteção delas no cuidado da atenção obstétrica no Distrito Federal. Brasília: Câmara Legislativa do Distrito Federal, 7 jun. 2018. Disponível em: http://www.sinj.df.gov.br/sinj/Norma/7005 64f2b3214c69a7c7c7897caab258/Lei_6144_07_06_2018.html. Acesso em: 20 jul. 2020.

ENEILE, M. Maternidades periféricas e o racismo obstétrico. “Ser mãe preta e periférica": sobreviventes do Estado genocida da população negra. Revista Reconexão Periferias, São Paulo, n. 10, p. 15-18, 2020.

EVITÁVEL. Direção: Júlia Morim. Rio de Janeiro: Fundação Oswaldo Cruz, 2019. Documentário (26 min).

FEDERICI, S. Calibã e a bruxa: mulheres, corpo e acumulação primitiva. São Paulo: Elefante, 2017.

FERNANDES, T. M. Doulagem. Uma atuação de resistência e democratização. Cadernos de Gênero e Diversidade, Salvador, v. 5, n. 4, p. 236-251, 2019.

FERREIRA, M. S. Pisando em óvulos: a violência obstétrica como uma punição sexual às mulheres. 2019. Tese. (Doutorado em Sociologia) - Faculdade de Ciências Sociais, Universidade Federal de Goiás, Goiânia, 2019.

FLEISCHER, S. Parteiras, buchudas e aperreios: uma etnografia do cuidado obstétrico não oficial na cidade de Melgaço, Pará. Belém: Paka-Tatu, 2010.

FRANÇA, R. L. de. A categoria 'violência obstétrica' no debate público brasileiro: uma reflexão interdisciplinar sobre movimentos, embates e articulações. 2020. Trabalho de Conclusão de Curso (Graduação em Ciência Política) - Universidade de Brasília, Brasília, 2020.

GINSBURG, F.; RAPP, R. (ed.). Conceiving the New World Order: the global politics of reproduction. Berkeley: University of California Press, 1995.

GONZALEZ, L. Racismo e sexismo na cultura brasileira. Ciências Sociais Hoje, São Paulo, v. 2, p. 223-244, 1984. 
HIRSCH, O. Parto natural, parto humanizado: perspectivas de mulheres de camadas populares e médias. Rio de Janeiro: Editora Fiocruz, 2019.

HIRSCH, O.; MENDONÇA, S. Violência obstétrica: um novo termo que engloba novas e velhas demandas. In: VIVEIROS DE CASTRO, T. D. (coord.) Violência obstétrica em debate: diálogos interdisciplinares. Rio de Janeiro: Lumen Juris, 2020. p. 73-90.

LEAL, M. do C. et al. A cor da dor: iniquidades raciais na atenção pré-natal e ao parto no Brasil. Cadernos de Saúde Pública, Rio de Janeiro, v. 33, p. 1-17, 2017.

LIMA, F. Bio-necropolítica: diálogos entre Michel Foucault e Achille Mbembe. Arquivos Brasileiros de Psicologia, Rio de Janeiro, v. 70, p. 20-33, 2018.

MARTIN, E. A mulher no corpo: uma análise cultural da reprodução. Rio de Janeiro: Garamond, 2006.

MATO GROSSO DO SUL. Lei $n^{\circ}$ 5217, de 26 de junho de 2018. Dispõe sobre a implantação de medidas de informação e de proteção à gestante e à parturiente contra a violência obstétrica no Estado de Mato Grosso do Sul, e dá outras providências. Campo Grande: Assembleia Legislativa do Estado do Mato Grosso do Sul, 26 jun. 2018. Disponível em: https://www.legisweb.com.br/legislacao/?id=361631. Acesso em: 20 jul. 2020.

MATTAR, L.; DINIZ, S. G. Hierarquias reprodutivas: maternidade e desigualdades no exercício de direitos humanos pelas mulheres. Interface, Botucatu, v. 16, n. 40, p. 107$119,2012$.

MÉXICO. Ley General de Acceso de las Mujeres a una Vida Libre de Violencia. Ciudad de México: Honorable Congreso de la Unión, 31 enero 2007. Disponível em: http://www. diputados.gob.mx/LeyesBiblio/pdf/LGAMVLV_010621.pdf. Acesso em: 20 jul. 2020.

MINAS GERAIS. Lei $n^{\circ} 23.175$, de 21 de dezembro de 2018. Dispõe sobre a garantia de atendimento humanizado à gestante, à parturiente e à mulher em situação de abortamento, para prevenção da violência na assistência obstétrica no Estado. Belo Horizonte: Assembleia Legislativa do Estado de Minas Gerais, 21 dez. 2018. Disponível em: https://www.legisweb.com.br/legislacao/?id=372848. Acesso em: 20 jul. 2020.

MOTT, M. L. Assistência ao parto: do domicílio ao hospital (1830-1960). Projeto História, São Paulo, v. 25, p. 197-219, 2002.

NAGAHAMA, E. E.; SANTIAGO, S. M. A institucionalização médica do parto no Brasil. Ciência \& Saúde Coletiva, Rio de Janeiro, v. 10, n. 3, p. 651-657, 2005.

PALHARINI, L.; FIGUERÔA, S. F. de M. Gênero, história e medicalização do parto: a exposição Mulheres e práticas de saúde. História, Ciências, Saúde - Manguinhos, Rio de Janeiro, v. 25, n. 4, p. 1039-1061, 2018. 
PANAMÁ. Ley 82 de 24 de octubre de 2013. Que adopta medidas de prevención contra la violencia en las mujeres y reforma el Código Penal para tipificar el femicidio y sancionar los hechos de violencia contra la mujer. Ciudad de Panamá: Asamblea Nacional, 24 oct. 2013. Disponível em: https://oig.cepal.org/sites/default/files/2013_ pan_ley82.pdf. Acesso em: 20 jul. 2020.

PERNAMBUCO. Lei $n^{\circ}$ 16.499, de 6 de dezembro de 2018. Estabelece medidas de proteção à gestante, à parturiente e à puérpera contra a violência obstétrica, no âmbito do Estado de Pernambuco. Recife: Assembleia Legislativa do Estado de Pernambuco, 6 dez. 2018. Disponível em: http://legis.alepe.pe.gov. br/texto.aspx?id=41220\&tipo=\#: :text=Estabelece $\% 20$ medidas $\% 20$ de $\% 20$ prote\%C3\%A7\%C3\%A30\%20\%C3\%A0,LEGISLATIVA\%20DO\%20ESTADO\%20DE\%20 PERNAMBUCO\%3A\&text=1\%C2\%B0\%20da\%20Lei\%20n,22\%20de\%20abril\%20 de\%202021. Acesso em: 20 jul. 2020.

PICHETH, S. F.; CRUBELLATE, J. M.; VERDU, F. C. A transnacionalização do parto normal no Brasil: um estudo das últimas cinco décadas. História, Ciências, SaúdeManguinhos, Rio de Janeiro, v. 25, n. 4, p. 1063-1082, 2018.

PULHEZ, M. M. Parem a violência obstétrica: a construção das noções de "violência" e "vítima" nas experiências de parto. Revista Brasileira de Sociologia da Emoção, João Pessoa, v. 12, n. 35, p. 544-564, 2013.

QUATTROCCHI, P. Epílogo. Violencia obstétrica, desde América Latina hasta Europa: similitudes y diferencias em el debate actual. In: QUATTROCCHI, P.; MAGNONE, N. (comp.). Violencia obstétrica em América Latina: conceptualización, experiencias, medición y estrategias. Remedios de Escalada: De la UNLa, Universidad Nacional de Lanús. 2020. p. 195-201.

RIBEIRO, J. C. Só corpo, sem mente: direitos reprodutivos, imaginário social e controle sobre os corpos das mulheres negras. PÓS, Brasília, v. 11, p. 179-199, 2012.

ROHDEN, F. Uma ciência da diferença: sexo e gênero na medicina da mulher. Rio de Janeiro: Editora da Fiocruz, 2001.

SANTA CATARINA. Lei n 17.097, de 17 de janeiro de 2017. Dispõe sobre a implantação de medidas de informação e proteção à gestante e parturiente contra a violência obstétrica no Estado de Santa Catarina. Florianópolis: Assembleia Legislativa do Estado de Santa Catarina, 17 jan. 2017. Disponível em: http://leis.alesc.sc.gov.br/ html/2017/17097_2017_lei.html. Acesso em: 20 jul. 2020. 
SÃO PAULO (Estado). Projeto de Lei $n^{\circ} 435 / 2019$. Garante à gestante a possibilidade de optar pelo parto cesariano, a partir da trigésima nona semana de gestação, bem como a analgesia, mesmo quando escolhido o parto normal. São Paulo: Assembleia Legislativa do Estado de São Paulo, 14 abr. 2019a. Disponível em: https://www.al.sp. gov.br/propositura/?id=1000262934. Acesso em: 20 jul. 2020.

SÃO PAULO (Estado). Lei $n^{0}$ 17.137, de 23 de agosto de 2019. Garante à parturiente a possibilidade de optar pela cesariana, a partir de 39 (trinta e nove) semanas de gestação, bem como a analgesia, mesmo quando escolhido o parto normal. São Paulo: Assembleia Legislativa do Estado de São Paulo, 23 ago. 2019b. Disponível em: https:// www.al.sp.gov.br/repositorio/legislacao/lei/2019/lei-17137-23.08.2019.html. Acesso em: 20 jul. 2020.

SCAVONE, L. Dar a vida e cuidar da vida: feminismo e ciências sociais. São Paulo: Editora Unesp, 2004.

SEGATO, R. Femigenocidio como crimen en el fuero internacional de los Derechos Humanos. In: SEGATO, R. La guerra contra las mujeres. Madrid: Traficantes de Sueños, 2016. p. 127-152.

SENA, L. M. Ameaçada e sem voz, como num campo de concentração: a medicalização do parto como porta e palco para a violência obstétrica. 2016. Tese (Doutorado em Saúde Coletiva) - Centro de Ciência da Saúde, Universidade Federal de Santa Catarina, Florianópolis, 2016.

SESIA, P. Violéncia obstétrica en México: la consolidación disputada de un nuevo paradigma. In: QUATTROCCHI, P.; MAGNONE, N. (comp.). Violencia obstétrica em América Latina: conceptualización, experiencias, medición y estrategias. Remedios de Escalada: De la UNLa, Universidad Nacional de Lanús, 2020. p. 3-29.

SHABOT, S. C. Making loud bodies "feminine": a feminist-phenomenological analisys of obstetric violence. Human Studies, [s. l.], v. 39, n. 2, p. 231-247, 2016. DOI: https://doi.org/10.1007/s10746-015-9369-x.

SILVA, F. L.; RUSSO, J. A. A porta da transformação só abre pelo lado de dentro: notas etnográficas sobre o processo de (trans)formação de si em cursos de capacitação de doulas. Cadernos de Gênero e Diversidade, Salvador, v. 5, n. 4, p. 162-180, 2019.

STENGERS, I. A proposição cosmopolítica. Revista do Instituto de Estudos Brasileiros, São Paulo, n. 69, p. 442-464, 2018. 
TEMPESTA, G. A. Trabalhando pelos bons vinculamentos. Reflexões antropológicas sobre o ofício das doulas. Anuário Antropológico, Brasília, v. 43, n. 1, p. 37-66, 2018.

UNITED NATIONS. A human rights-based approach to mistreatment and violence against women in reproductive health services with a focus on childbirth and obstetric violence. [S. l.]: UN, 2019.

VALLANA SALA, V. V. La enfermedad normal: aspectos históricos y políticos de la medicalización del parto. Sexualidad, Salud y Sociedad: revista latinoamericana, Rio de Janeiro, n. 34, p. 90-107, 2020.

VENEZUELA. Ley Orgánica sobre el Derecho de las Mujeres a una Vida Libre de Violencia. Gaceta Oficial de la República Bolivariana de Venezuela, Caracas, n. 36.668, p. 354064-354075, 23 abr. 2007. Disponível em: https://www.acnur.org/fileadmin/ Documentos/BDL/2008/6604.pdf. Acesso em: 20 jul. 2020.

VENTURI G.; GODINHO, T. Mulheres brasileiras e gênero nos espaços público e privado: uma década de mudanças na opinião pública. São Paulo: Fundação Perseu Abramo: Editora SESC SP, 2013.

VIEIRA, E. M. A medicalização do corpo feminino. 2. reimp. Rio de Janeiro: Editora Fiocruz, 2015.

WORLD HEALTH ORGANIZATION. Appropriate technology for birth. The Lancet, [s. l.], v. 326, n. 8452, p. 436-437, 1985. DOI: https://doi.org/10.1016/S0140-6736(85)92750-3.

Recebido: 21/07/2020 Aceito: 06/07/2021 | Received: 7/21/2020 Accepted: 7/6/2021 